\title{
Randomised controlled trial of telemonitoring with addition of daily forced oscillation in older people with COPD and co-morbidity (CHROMED)
}

\author{
Pompilio P, Zanaboni P, Bergmo T, Grzetic \\ Romcevic $T$, Isetta $V$, Janson C, Malinovschi A, \\ Marusic D, Middlemass J, Montserrat J, Munaro \\ G, Prikk K, Sepper R, Siriwardena N, Calverley P, \\ Dellaca R, Rosso R and Walker PP
}




\section{Conflict of Interest}

- Dr Paul Walker has received payment to lecture at education meetings from Astra Zeneca, Chiesi and Novartis. His department has received funding to recruit to research studies from GlaxoSmithKline, Bayer and Pharmaxis (no personal funding)

- Prof Peter Calverley has advised pharmaceutical companies about the conduct of clinical trials in COPD, including GSK, Boehringer Ingelheim, Novartis, Takeda Nycomed, Chiesi and Almirall. He has spoken at meetings supported in whole or in part by these companies

- Dr Pasquale Pompilio and Prof Raffaele Dellaca own shares in Restech srl that produces the Resmon Pro Diary 


\section{Telemonitoring in People with COPD}

- Most randomised controlled trials of remote monitoring in COPD have typically monitored symptoms via a remote electronic platform with basic physiological information (including $\mathrm{FEV}_{1}$ ) collected in some cases

- Many studies are modest in size and outcomes generally negative

- The largest study by Pinnock $\mathrm{H}$ et al (BMJ 2013) monitored symptoms, treatment and $\mathrm{O}_{2}$ saturations and found no impact on hospitalisation or health status

- It is currently not clear that telemonitoring provides added value to self-management though there may be benefit in sub-groups 


\section{CHROMED: Clinical trial of elderly patients with multiple disease}

- The study aimed to test the health and economic effectiveness of adopting an innovative homemonitoring platform based on simple physiological measurement (forced oscillation) to manage elderly COPD with comorbidities

- EU-funded (FP7) multi-centre clinical trial involving 300 patients in 6 European clinical centers with 3 technical partners

- The study ran from October 2013 to March 2016
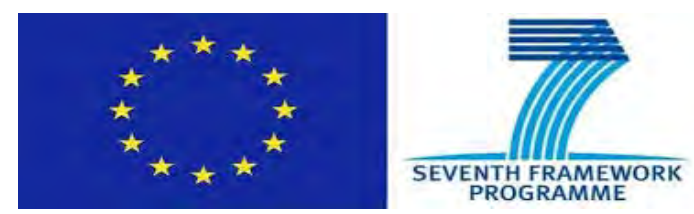


\section{Clinical and Technical Centres}

Clinical Centres

- Aintree Hospital, University of Liverpool, UK (38 patients)

- University of Lincoln, UK (32 patients)

- University of Barcelona, Spain (60 patients)

- Uppsala University, Sweden (60 patients)

- Tallinn University of Technology, Estonia (78 patients)

- Bolnisnica Sežana Zavod, Slovenia (32 patients)

$\underline{\text { Technical Centres }}$

- Elettronica Biomedicale (EBM), Italy: project manager

- RESTECH srl, Italy: technical manager

- University Hospital of North Norway (UNN): impact manager 


\section{Study Design}

- 300 subjects were randomised 1:1 to either home monitoring (monitored) or not (control) for 9 months

- Home monitoring consisted of:

- Daily measurement of lung mechanics and breathing pattern using Resmon Pro Diary

- plus for heart failure patients: daily pulse, $\mathrm{BP}, \mathrm{O}_{2}$ sats and weight

- Daily symptom questionnaires recorded by all (not used to generate alerts) and multiple other questionnaires including EQ5D, EQ5D-VAS, CAT, PRQ, healthcare utilisation, satisfaction and MHLF (heart failure patients only)

- Primary outcomes: the study was powered with $90 \%$ chance to find $25 \%$ increase in time to first hospitalisation (TTFH) and $15 \%$ improvement in quality of life measured by EQ5D at 9 months 


\section{Resmon Pro Diary}

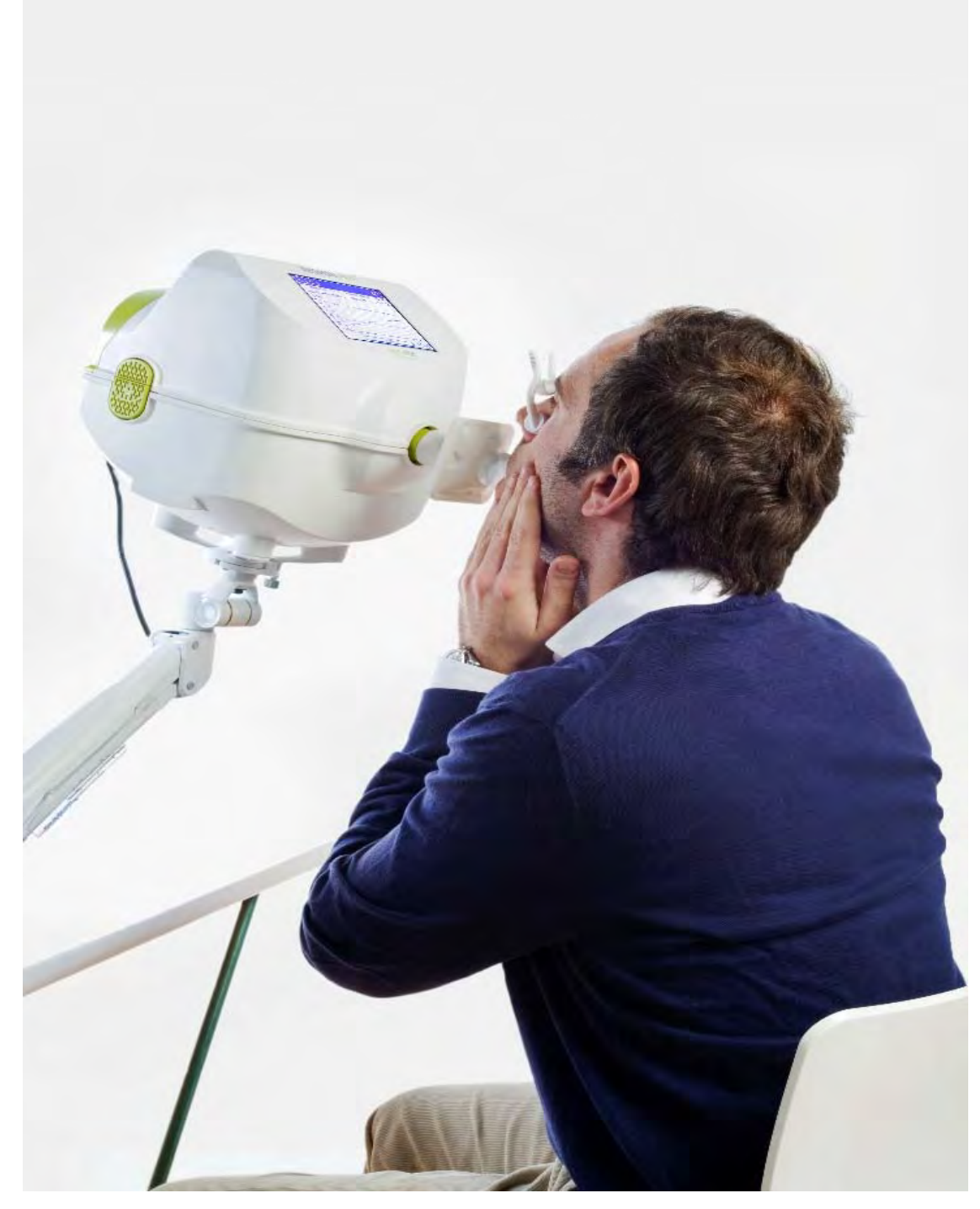

- Set up in the home of the monitored subjects

- Daily 2 minute forced oscillation recording with cheeks compressed and wearing nose clips

- Measurement of airway resistance and reactance by forced oscillation 


\section{Management of Alerts}

- The alert algorithm was based on a previous study in Italy recruiting people with severe COPD

- Subjects were recruited when clinically stable and underwent a period of monitoring (usually 1-2 weeks) to establish their baseline

- A sustained worsening in forced oscillation measurements led to an alert sent to the clinical centre

- It was the responsibility of the clinical centre to contact study subject and decide if action was required

- Alerts were also sent where data was missing with the option to 'pause'

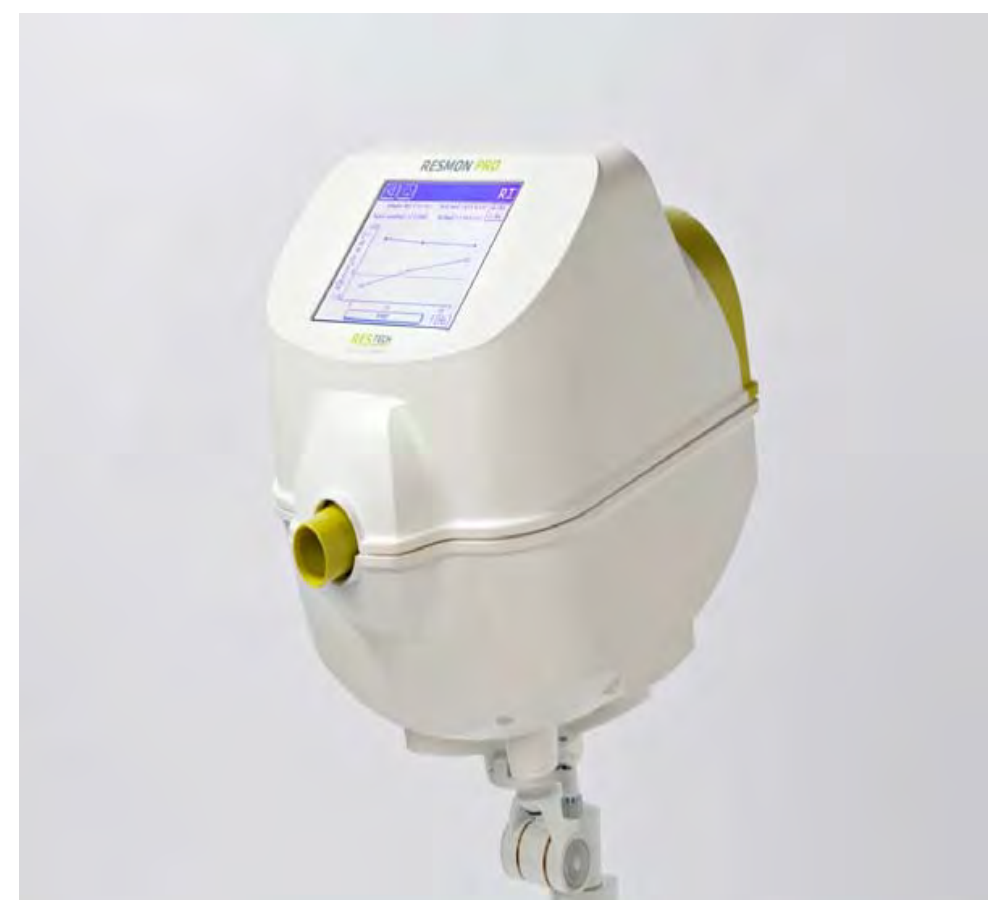




\section{Inclusion Criteria}

- At least moderate COPD - FEV $1 / F V C<0.7$ and $\mathrm{FEV}_{1}<80 \%$ predicted

- At least 10 pack years cigarette smoking

- Aged at least 60 years but sites requested to recruit 65 years or older where possible

- At least 1 COPD exacerbation and/or hospitalisation during the previous year

- At least 1 co-morbidity - CCF (LVSD on echo), IHD, hypertension, SDB (AHI >5), OHS, treated hyperlipidaemia, treated osteoporosis

- Mobile phone coverage at home and able to use equipment

- No plan for extended absence from home during the study 


\section{Diagram of Study flow}

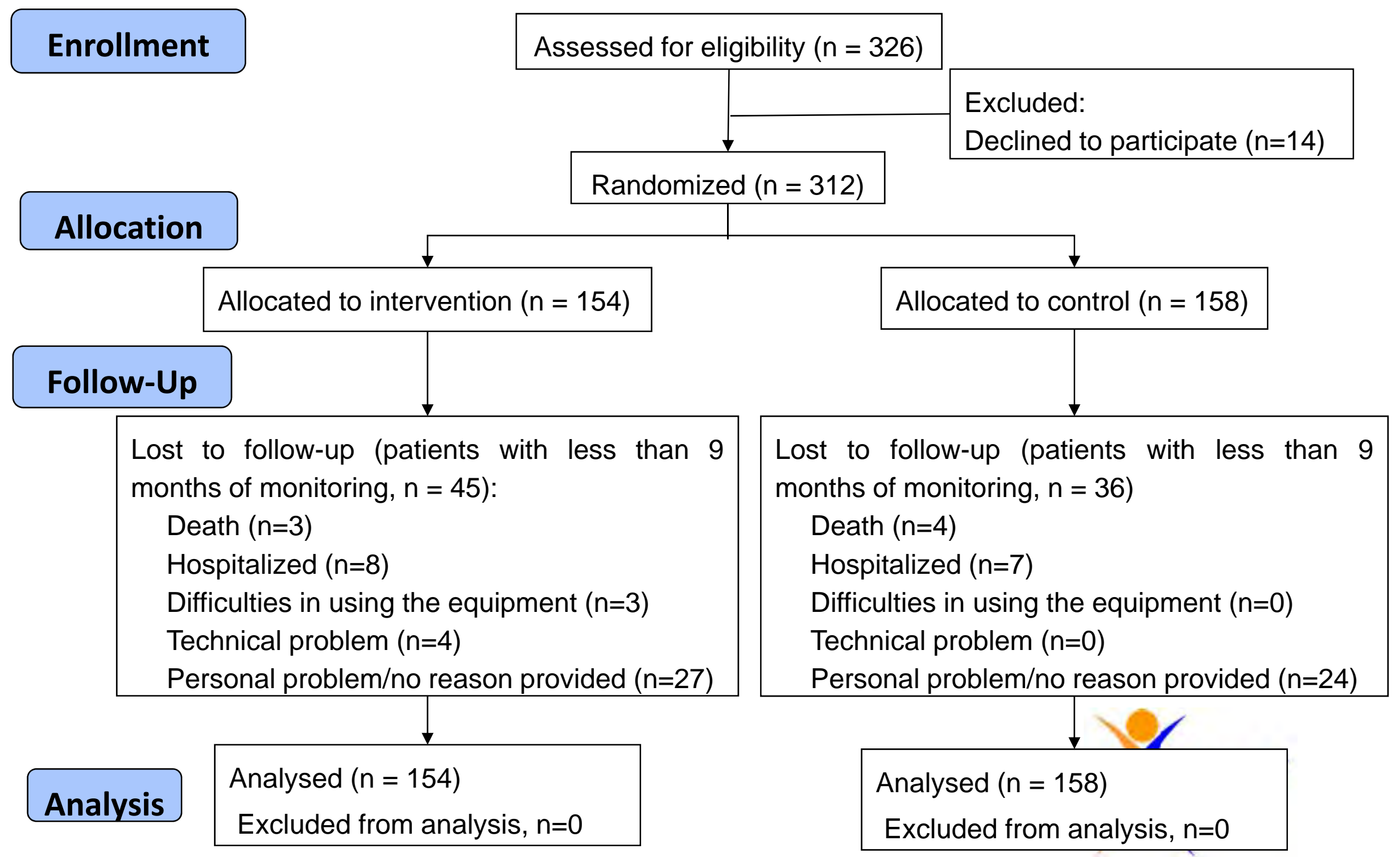




\section{Baseline Characteristics}

\begin{tabular}{|c|c|c|}
\hline & Monitored ( $n=154$ ) & Control (n=158) \\
\hline Sex (male/female) & $101 / 53$ & $105 / 53$ \\
\hline Age (years) & 71 & 71 \\
\hline Pack years & 40 & 40.5 \\
\hline $\mathrm{FEV}_{1}$ (L/\% predicted) & $1.3(49.4 \%)$ & $1.3(50.4 \%)$ \\
\hline $\mathrm{FEV}_{1} / \mathrm{FVC}$ & 0.5 & 0.51 \\
\hline SGRQ & 46.2 & 50.9 \\
\hline Exacerbation last year & $1=41 \%, 2+=59 \%$ & $1=37 \%, 2+=63 \%$ \\
\hline Hospitalisation last year & $42 \%$ & $41 \%$ \\
\hline GOLD II/III/IV (\%) & $47 / 36 / 15$ & $48 / 39 / 11$ \\
\hline \multicolumn{3}{|l|}{ Co-morbidity (\%): } \\
\hline CCF & 12 & 8 \\
\hline IHD & 25 & 23 \\
\hline$C C F+I H D$ & 12 & 13 \\
\hline Hypertension & 72 & 68 \\
\hline OSA/OHS & 11 & 6 \\
\hline Osteoporosis & 17 & 15 \\
\hline Hyperlipidaemia & 53 & 58 \\
\hline
\end{tabular}




\section{Data Completeness}

\begin{tabular}{|l|c|c|}
\hline & Monitor & Control \\
\hline Resmon Pro & $89 \%$ & NA \\
\hline $\begin{array}{l}\text { COPD } \\
\text { questionnaire }\end{array}$ & $89 \%$ & $85 \%$ \\
\hline $\begin{array}{l}\text { CCF } \\
\text { questionnaire }\end{array}$ & $97 \%$ & $71 \%$ \\
\hline
\end{tabular}

Excludes:

- Days in hospital

- Days absent from home on holiday/vacation 


\section{Overall Study Results - Time to First Hospitalisation}

All cause

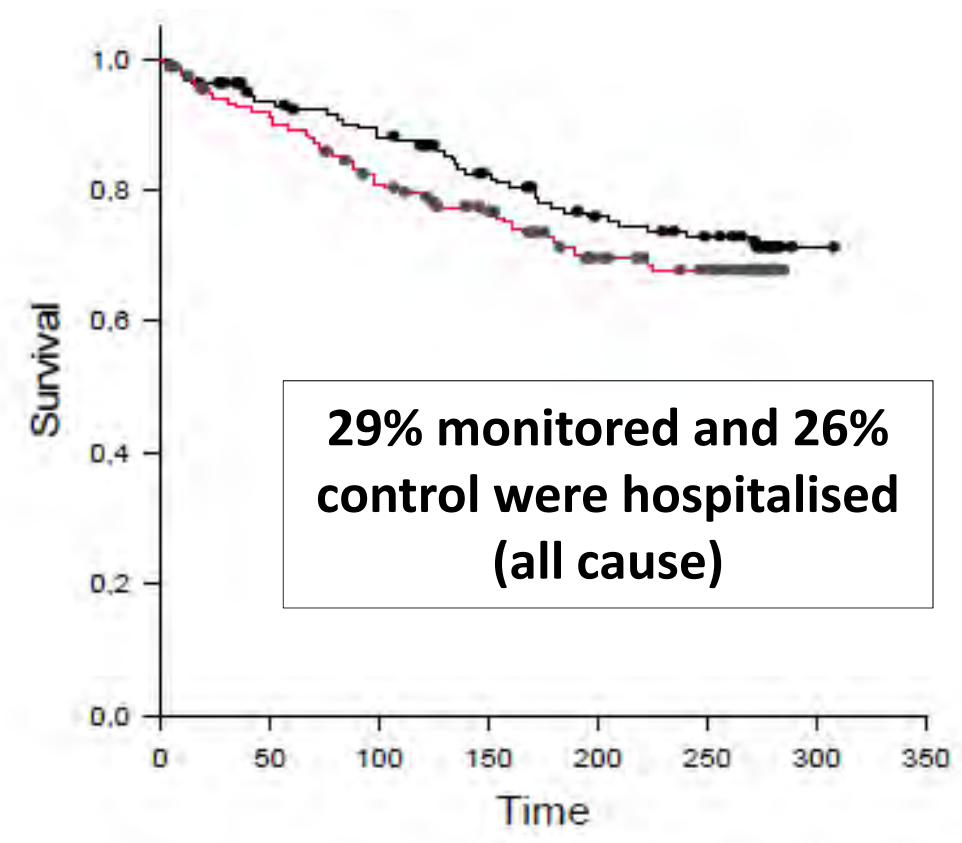

Respiratory

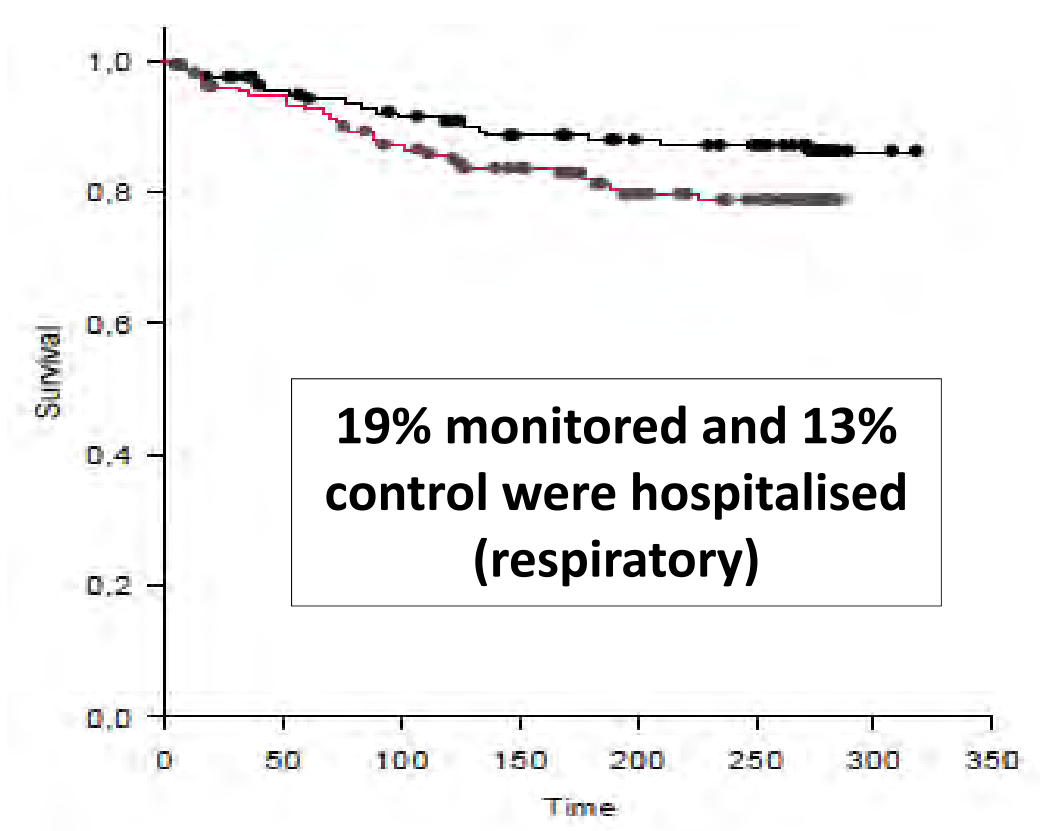

$$
\text { Black }=\text { control } \quad \text { Red } / \text { grey }=\text { monitored }
$$

Mean TTFH all cause: $\quad$ Monitored: 224 days

Mean TTFH respiratory: Monitored: 244 days
Control: 225 days (ns)

Control: 287 days (ns) 


\section{Hospitalisation Number and Bed Days}

\begin{tabular}{|l|c|c|c|}
\hline & Monitored $(\mathbf{n = 1 5 4 )}$ & Control $(\mathbf{n = 1 5 8 )}$ & $\mathrm{p}$ value \\
\hline Hospitalisation overall & 79 & 103 & $\mathrm{~ns}$ \\
\hline Respiratory & 45 & 59 & $\mathrm{~ns}$ \\
\hline Cardiac & 7 & 5 & $\mathrm{~ns}$ \\
\hline & & & $\mathrm{ns}$ \\
\hline Days in hospital & 329 & 650 & $\mathrm{~ns}$ \\
\hline Respiratory & 256 & 543 & $\mathrm{~ns}$ \\
\hline Cardiac & 45 & 18 & \\
\hline
\end{tabular}

\section{EQ5D}

\begin{tabular}{|l|c|c|c|}
\hline & Monitor & Control & p value \\
\hline Baseline & 0.64 & 0.66 & $\mathrm{~ns}$ \\
\hline 3 months & 0.66 & 0.63 & $\mathrm{~ns}$ \\
\hline 6 months & 0.64 & 0.68 & $\mathrm{~ns}$ \\
\hline 9 months & 0.64 & 0.64 & $\mathrm{~ns}$ \\
\hline
\end{tabular}




\section{Cost Effectiveness}

\begin{tabular}{|l|c|c|}
\hline & Monitor* & Control* \\
\hline Hospital & $€ 2039$ & $€ 3318$ \\
\hline Community & $€ 1398$ & $€ 1513$ \\
\hline \multicolumn{1}{|c|}{ Healthcare sub total } & $€ 3437$ & $€ 4831$ \\
\hline Medical alarms & $€ 110$ & 0 \\
\hline Technical alarms & $€ 393$ & 0 \\
\hline Equipment & $€ 675$ & 0 \\
\hline \multicolumn{1}{|c|}{ Technical sub total } & $€ 1177$ & $€ 0$ \\
\hline Total & $€ 4615$ & $€ 4831$ \\
\hline & & hromed \\
\hline
\end{tabular}




\section{Subgroup: Individuals with 1 or more hospitalization in the previous year}

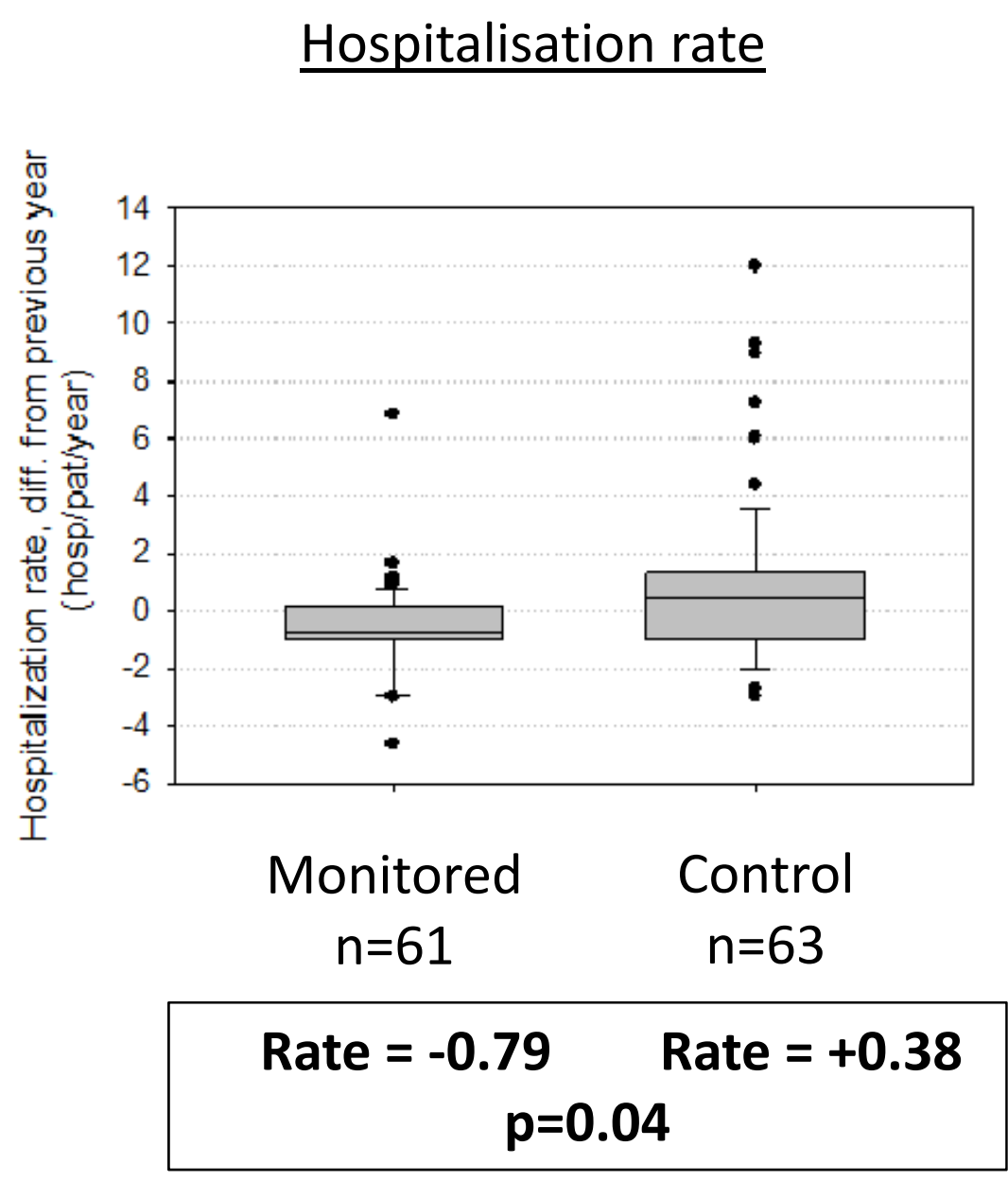

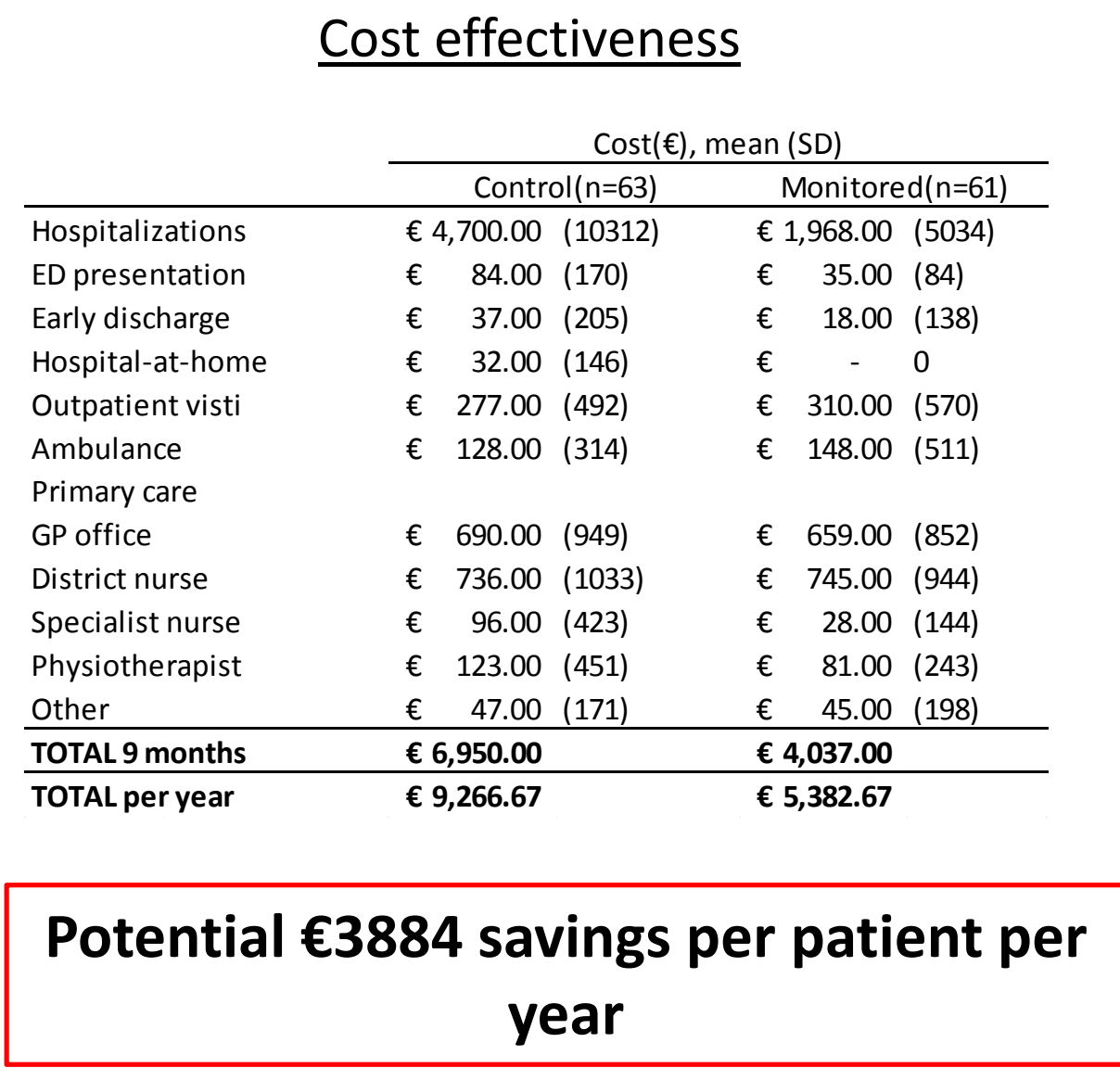




\section{Conclusions}

- Daily monitoring with forced oscillation did not change time to first hospitalisation, hospitalisation rate or health status

- In sub-group analysis people who were hospitalised in the previous year showed a lower hospitalisation rate with a potential significant cost saving and they may benefit from telemonitoring and earlier treatment 


\section{With thanks to...}

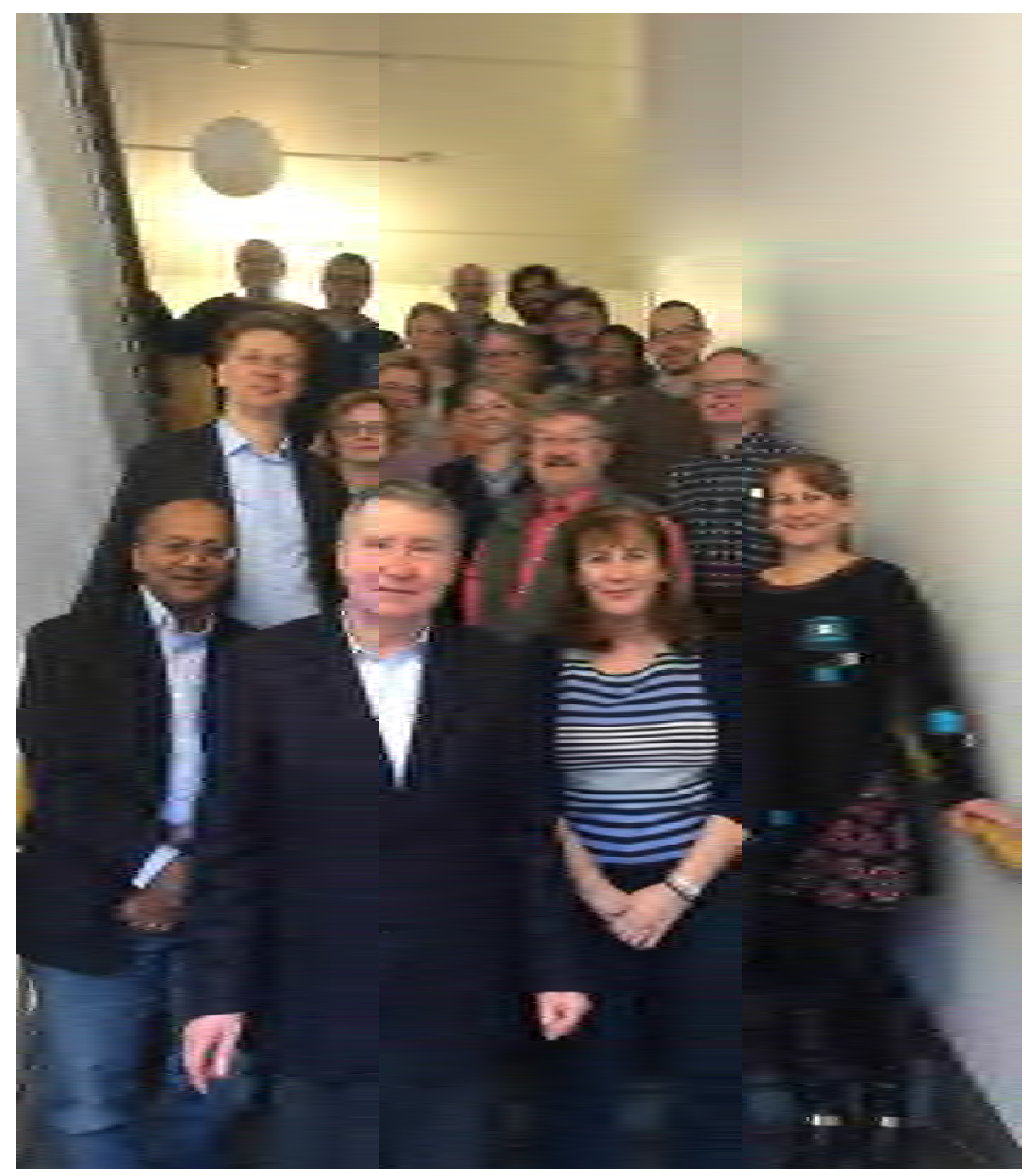

RESTECH srl: Pompilio P, Dellaca R, Macis R Elettronica Biomedicale (EBM): Munaro $G$, Rosso R, Venere Angonese G, Castellani A University Hospital of North Norway: Zanaboni P, Bergmo T, Asheim-Olsen $\mathrm{H}$, Knarvic U

Bolnisnica Sežana Zavod: Grzetic Romcevic T, Marusic D, Miklavec D, Sonc S, Rota B University of Barcelona: Isetta $V$, Montserrat J, Farre R, Dalmases M Uppsala University: Janson $C$, Malinovschi A, Omar S, Nisser $K$

Tallinn University of Technology:

Prikk K, Sepper R,

University of Lincoln: Middlemass J, Siriwardena N

University of Liverpool: Keogan L, Dobson S, Calverley $\mathrm{P}$, Walker $\mathrm{P}$ 


\section{Additional slides}




\section{Alerts}

- 793 respiratory alerts $=$ median (IQR) 0.55 (0.270.87 ) alerts/patient/month

- 647 'clustered' (worsening) respiratory alerts $=$ median (IQR) 0.53 (0.29-0.66) alerts/patient/month

- $50 \%$ of alerts associated with a change in at least one symptom

- 222/647 (34\%) required intervention after telephone discussion
- Symptoms

- Breathlessness 22\%

- Cough 14\%

- Change in phlegm $14 \%$

- Sore throat or 'cold' $14 \%$

- Less energy $12 \%$

- Worse sleep $6 \%$

- Wheeze $5 \%$

- Treatment

- Change in current treatment 29\%

- Addition of treatment $18 \%$

- Visit by doctor or nurse $34 \%$

- Hospitalisation 3\%

- Suggested treatment refused 9\% 


\section{Drop Out}

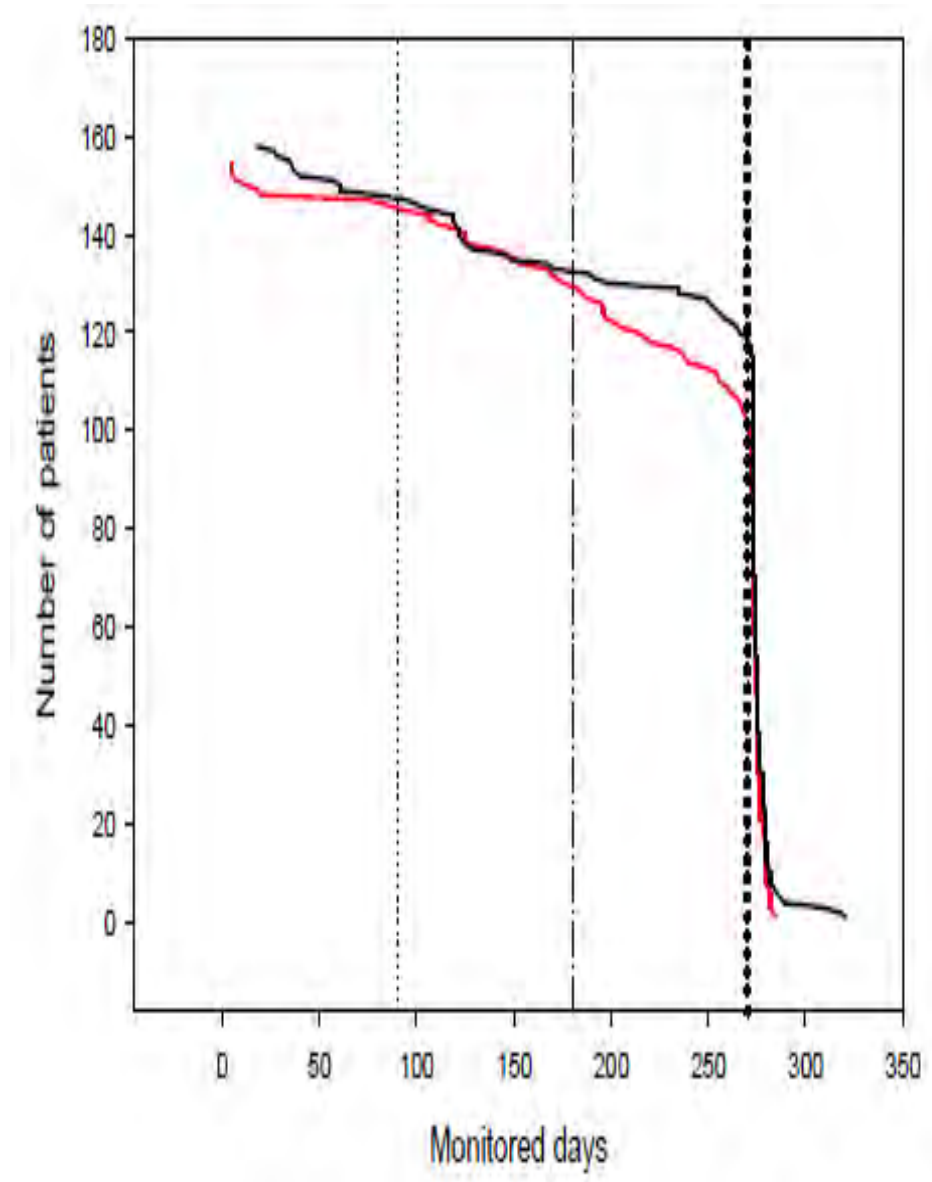

- By the end of the study drop out was:

- $45(29 \%)$ in monitored arm

- $36(23 \%)$ in control arm

- This did not differ significantly between groups 